\title{
ESTUDO GRANULOMÉTRICO EM SISTEMA DE FILTRAÇÃO DIRETA PARA TRATAMENTO DE ÁGUA DE ABASTECIMENTO COM USO DE COAGULANTES ORGÂNICOS E INORGÂNICOS
}

\author{
EDILAINE REGINA PEREIRA, \\ RENATO AKIRA IOSHIMURA, \\ JOSEANE DEBORA PERUÇO THEODORO, \\ BRUNA RICCI BICUDO, \\ FELLIPE JHORDÃ LADEIA JANZ.
}

\begin{abstract}
RESUMO - A presente pesquisa teve como objetivo comparar o desempenho do coagulante natural extraído da semente da Moringa oleifera com o desempenho do coagulante químico Sulfato de Alumínio no tratamento de água, e verificar a melhor granulometria da areia utilizada no processo de filtração direta. Para tal, foram realizados ensaios no equipamento Jar-Test seguido de filtração descendente direta. A concentração para ambos os coagulantes foi de $300 \mathrm{mg} . \mathrm{L}^{-1}$. Para a filtração foram utilizadas três granulometrias distintas: G1 (até $0,425 \mathrm{~mm}), \mathrm{G} 2(0,425$ a $0,850 \mathrm{~mm})$ e G3 $(0,850$ a $1,70 \mathrm{~mm})$. Os parâmetros analisados foram: $\mathrm{pH}$, cor aparente, turbidez e condutividade elétrica. Os valores de $\mathrm{pH}$, apesar da discreta variação, permaneceram dentro do padrão exigido pela Portaria $\mathrm{n}^{\circ} 5$ da Consolidação. A condutividade elétrica sofreu um aumento para ambos os coagulantes devido a presença de sais e proteínas (no caso da Moringa oleifera), e íons de alumínio (no caso do Sulfato de alumínio) na água tratada. Após o processo de filtração a eficiência de remoção de cor aparente dos coagulantes aumentou significativamente, tendo a granulometria G3 apresentado o melhor resultado para o coagulante orgânico (98\%) e G2 apresentado melhor resultado para o coagulante inorgânico (96\%). O tratamento utilizando o extrato da semente de Moringa oleifera associado à filtração com granulometria G3 (0,850 a 1,70 mm) foi a associação que obteve os resultados mais satisfatórios, comprovando a eficiência do coagulante orgânico associado ao processo de filtração no tratamento de água.
\end{abstract}

PALAVRAS-CHAVE - Tamarindus indica L.; Filtração direta; Granulometria; Tratamento de água.

\section{INTRODUÇÃO}

A água é um bem natural finito e vulnerável de muita importância para a qualidade de vida dos seres humanos e para o desenvolvimento socioeconômico de qualquer nação. O seu uso tem grande importância no desenvolvimento de diversas atividades econômicas como, por exemplo, na produção agrícola e nas indústrias. Existe uma estreita relação entre a acessibilidade à água de boa qualidade, adequação da infraestrutura de saneamento e a saúde humana. Com o avanço tecnológico e o aumento da população novos hábitos de consumo surgiram, e assim o aumento significativo da demanda dos recursos naturais, principalmente da água [14].

As águas naturais podem apresentar substâncias e microrganismos prejudiciais à saúde. Muitas doenças provêm de água de má qualidade. Especificamente na etapa de coagulação geralmente são utilizados coagulantes inorgânicos, de origem química, como o sulfato de alumínio, o cloreto férrico e o sulfato férrico, que são eficientes na remoção de impurezas da água. A utilização de coagulantes químicos está gerando discussão, pois a presença de metais residuais na água, como o alumínio, vem sendo associada a um possível surgimento de doenças neurológicas nos seres humanos [17]. Além disso, os resíduos gerados nas Estações de Tratamento de Água (ETA's), que são dispostos diretamente no solo ou em corpos d'água, podem ocasionar a contaminação da água em questão.

Devido a esses problemas associados ao uso de coagulantes químicos, despertou-se um interesse em buscar novos compostos como alternativa para o uso como coagulantes. Dentre os estudados pode-se citar o extrato salino da semente de Moringa oleifera. Além de ser um coagulante natural, apresenta importantes vantagens em relação aos coagulantes convencionais, sendo biodegradável, de baixo custo, nãotóxico, além de não alterar o $\mathrm{pH}$ da água e apresentar boa remoção de cor e turbidez. O uso da semente também produz menor quantidade de lodo e com menores teores de metais 
[7].

Outro fator de grande importância dentro do processo de tratamento de água é a determinação da granulometria do material filtrante. Na pesquisa realizada por LIMA et al. [10] foi estudada a distribuição granulométrica de areias empregadas em filtros de uma ETA com objetivo de analisar a influência da granulometria sobre a eficiência da filtração, neste trabalho constatou-se que as areias da ETA não apresentaram uma granulometria definida, destacando-se que areias de diferentes granulometrias influenciam na qualidade do tratamento de água.

Diante de tais constatações, os objetivos desta pesquisa consistiram em avaliar a eficiência do coagulante extraído da semente de Moringa oleifera no processo de coagulação/floculação/sedimentação/filtração no tratamento de água, comparando-a com o coagulante inorgânico Sulfato de Alumínio, e ainda, verificar a melhor granulometria de areia utilizada no processo de filtração direta.

\section{MATERIAL E MÉTODOS}

A água utilizada para a realização desse estudo foi captada do Ribeirão Jacutinga, um corpo d'água de Classe II situado na região Norte do Paraná.

As amostras de água foram coletas em galões de 20 litros e encaminhadas para o Laboratório de Recursos Hídricos da Universidade Tecnológica Federal do Paraná - Campus Londrina.

Antes da execução dos ensaios foi necessário realizar o preparo das soluções coagulantes. Para a extração coagulante da semente de Moringa oleifera foi preciso extrair seus componentes ativos, para tal extração utilizou-se 10 gramas de semente de Moringa oleifera descascada manualmente e 1L de água destilada medida em balão volumétrico, ambos os componentes foram triturados no liquidificador e posteriormente misturados à uma solução salina de concentração de $1 \mathrm{Mol} / \mathrm{L}$ de $\mathrm{NaCl}$, em seguida a mistura foi peneirada em um coador de pano.

Para o preparo da solução coagulante de Sulfato de Alumínio $\left(\mathrm{Al}_{2}\left(\mathrm{SO}_{4}\right)_{3}\right)$ foi diluído $1 \mathrm{~g}$ do produto em $1 \mathrm{~L}$ de água destilada. O sal utilizado têm peso molecular $342,14 u$, densidade de $2.672 \mathrm{gcm}^{-3}$ (sólido) e solubilidade em água igual a $870 \mathrm{gL}^{-1}$.

Tanto para o coagulante natural extraído da semente de Moringa oleifera quanto para o coagulante químico sulfato de alumínio, a concentração que utilizada foi de $300 \mathrm{mgL}^{-1}$.

Para a realização dos ensaios foi utilizada a metodologia Jar-Test objetivando a determinação da condição ótima para que ocorra a coagulação/floculação/sedimentação de partículas presentes na água por meio do tempo de agitação e gradiente de agitação.

Os jarros, do equipamento Jar-test, tiveram seu volume completado com a água de abastecimento e em seguida foram adicionados os coagulantes. Posteriormente as soluções presentes nos jarros foram submetidas a agitação rápida de 150rpm durante 3 minutos (processo de coagulação), seguida de uma agitação lenta de $15 \mathrm{rpm}$ durante 10 minutos (processo de floculação), por fim o equipamento foi desligado (processo de sedimentação) (adaptado [19|).

Após o desligamento do aparelho foram realizadas coletas de amostras de todos os jarros de 10 em 10 minutos perfazendo os tempos de 3,13 e 23 minutos.

Para o processo de filtração foram construídos seis filtros em paralelo adaptados logo abaixo do Jar-Test de forma que a água saísse diretamente do jarro para os filtros após 23 minutos de sedimentação, simulando uma filtração direta com fluxo descendente, conforme Figura 1.

Para a construção dos filtros foi adaptada uma estrutura metálica que suporta os filtros de garrafas de Polietileno Tereftalato (PET). As camadas filtrantes foram compostas por cascalho e areia, e o suporte para o meio filtrante composto por algodão e filtro de papel.

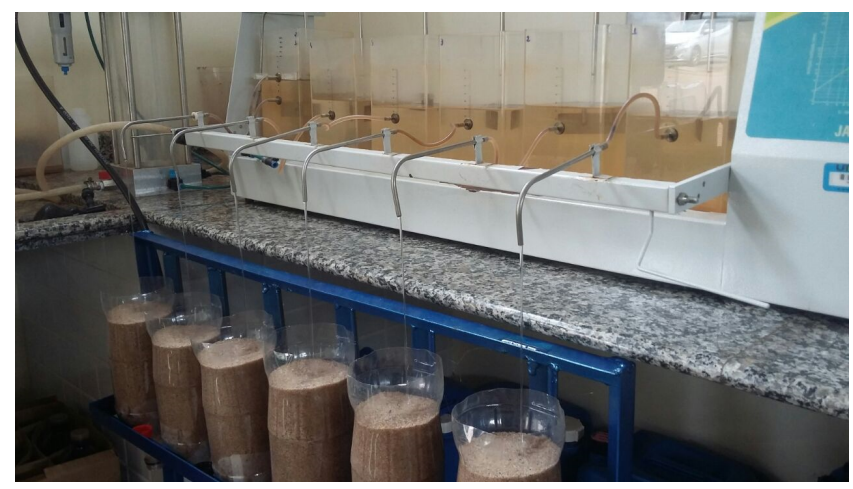

Figura 1. Filtração direta com fluxo descendente. (Fonte: BICUDO, 2017)

Foram testadas três faixas granulométricas sendo estas: G1: de até $0,425 \mathrm{~mm}$; G2: de 0,425 a $0,850 \mathrm{~mm}$; e G3: de 0,850 a $1,70 \mathrm{~mm}$. Após a filtração, a água foi coletada para análise.

Para todas as amostras foram analisados os seguintes parâmetros: turbidez, cor aparente, condutividade elétrica e $\mathrm{pH}$. As análises foram efetuadas conforme os procedimentos descritos pelo Standard Methods of Examination of Water and Wastewater [1].

Todas as análises foram realizadas em duplicata objetivando diminuir possíveis erros e posteriormente tratar os dados estatisticamente. Para a análise estatística foi utilizado o delineamento inteiramente casualizado, em esquema fatorial $2 \times 3$. O modelo estatístico considerou, além do efeito dos fatores "Coagulante" (em dois níveis), "Tempo" (em três níveis) ou "Granulometria" (em três níveis), o efeito da interação entre os fatores.

\section{RESULTADOS E DISCUSSÃO}

A Tabela 1 mostra a variação média de pH após o processo de filtração.

Analisando os dados dispostos na Tabela 1 é possível observar que o $\mathrm{pH}$ da água de abastecimento tratada com ambos os coagulantes não sofreu grandes alterações quando comparado ao $\mathrm{pH}$ bruto de 6,98. Logo, é possível afirmar que a filtração, bem como as diferentes granulometrias de areia, não tiveram influência sobre o $\mathrm{pH}$ da água tratada. 
Tabela 1. Variação média do pH após a filtração.

\begin{tabular}{|c|c|c|}
\hline $\begin{array}{c}\text { Variação de } \\
\text { Granulometria }\end{array}$ & $\begin{array}{c}\text { Sulfato de } \\
\text { Alumínio }\end{array}$ & Moringa oleifera \\
\hline G1 & 6,91 & 6,86 \\
\hline G2 & 7,14 & 6,94 \\
\hline G3 & 7,15 & 6,75 \\
\hline
\end{tabular}

Após o ensaio, tem-se que para ambos os coagulantes o pH está de acordo com a legislação Portaria $\mathrm{N}^{\circ} 5$ da Consolidação do Ministério da Saúde [2], a qual recomenda, que no sistema de distribuição, o pH seja mantido na faixa de 6,0 a 9,5 .

Encontram-se na Tabela 2 as comparações entre os valores médios de $\mathrm{pH}$ após a filtração resultantes do teste de Tukey.

Tabela 2. Comparações de médias pelo teste de Tukey para o pH.

\begin{tabular}{|c|c|c|c|}
\hline \multirow{2}{*}{ Coagulante } & \multicolumn{3}{|c|}{ Granulometria } \\
\cline { 2 - 4 } & G1 & G2 & G3 \\
\hline Moringa oleifera & $6,860 \mathrm{a}$ & $6,935 \mathrm{a}$ & $6,750 \mathrm{a}$ \\
\hline Sulfato de alumínio & $6,910 \mathrm{a}$ & $7,135 \mathrm{~b}$ & $7,205 \mathrm{~b}$ \\
\hline \multirow{3}{*}{ Granulometria } & \multicolumn{3}{|c|}{ Coagulante } \\
\cline { 2 - 3 } & $\begin{array}{c}\text { Moringa } \\
\text { oleifera }\end{array}$ & $\begin{array}{c}\text { Sulfato de } \\
\text { Alumínio }\end{array}$ \\
\hline G1 & $6,860 \mathrm{a}$ & $6,910 \mathrm{a}$ \\
\hline G2 & $6,935 \mathrm{a}$ & $7,135 \mathrm{ab}$ \\
\hline G3 & $6,750 \mathrm{a}$ & $7,205 \mathrm{~b}$ \\
\hline
\end{tabular}

Ao analisar a Tabela 2 nota-se que a granulometria G1 obteve resultados estatisticamente iguais para ambos os coagulantes, já as granulometrias G2 e G3 obtiveram resultados estatisticamente diferentes em que o Sulfato de Alumínio apresenta médias superiores aos resultados do tratamento com a extração da semente da Moringa oleifera.

É possível verificar também que para o coagulante orgânico as três granulometrias apresentaram resultados estatisticamente iguais, para o Sulfato de Alumínio o mesmo não ocorreu, para o tratamento com o coagulante químico, as granulometrias G1 e G2 apresentaram diferença nas médias consideradas não significativas, assim como G2 e G3. Porém, G1 e G3 possuem médias estatisticamente diferentes.

Os valores encontrados por PEREIRA et al. [13] e BICUDO et al. [3] foram semelhantes aos valores encontrados no presente trabalho, apresentando também pouca variação no $\mathrm{pH}$, sendo esta de menos de uma unidade de $\mathrm{pH}$, e valores do parâmetro sempre próximos a 7.

As Tabelas 3 e 4 apresentam os valores médios de condutividade elétrica após o processo de filtração assim como a comparação de médias pelo teste de Tukehy para a condutividade elétrica.

De acordo com a Tabela 3, os valores de condutividade elétrica após a filtração sofreram alterações tanto para o coagulante inorgânico quanto para o coagulante orgânico nos diferentes filtros utilizados. Para o tratamento com
Tabela 3. Condutividade Elétrica média após a filtração.

\begin{tabular}{|c|c|c|}
\hline $\begin{array}{c}\text { Variação de } \\
\text { Granulometria }\end{array}$ & $\begin{array}{c}\text { Sulfato de } \\
\text { Alumínio }\end{array}$ & Moringa oleifera \\
\hline G1 & 0,47 & 0,40 \\
\hline G2 & 0,41 & 0,25 \\
\hline G3 & 0,34 & 0,40 \\
\hline
\end{tabular}

Tabela 4. Comparações de médias pelo teste de Tukey para os desdobramentos para a Condutividade Elétrica

\begin{tabular}{|c|c|c|c|}
\hline \multirow{2}{*}{ Coagulante } & \multicolumn{3}{|c|}{ Granulometria } \\
\cline { 2 - 4 } & G1 & G2 & G3 \\
\hline Moringa oleifera & $0,400 \mathrm{a}$ & $0,250 \mathrm{a}$ & $0,400 \mathrm{a}$ \\
\hline Sulfato de alumínio & $0,465 \mathrm{~b}$ & $0,405 \mathrm{~b}$ & $0,335 \mathrm{~b}$ \\
\hline \multirow{3}{*}{ Granulometria } & \multicolumn{3}{|c|}{ Coagulante } \\
\cline { 2 - 4 } & $\begin{array}{c}\text { Moringa } \\
\text { oleifera }\end{array}$ & $\begin{array}{c}\text { Sulfato de } \\
\text { Alumínio }\end{array}$ \\
\hline G1 & $0,40 \mathrm{a}$ & $0,465 \mathrm{a}$ \\
\hline G2 & $0,25 \mathrm{~b}$ & $0,405 \mathrm{ab}$ \\
\hline G3 & $0,40 \mathrm{a}$ & $0,335 \mathrm{~b}$ \\
\hline
\end{tabular}

Sulfato de Alumínio a maior diferença apresentada foi de $0,13 \mathrm{mScm}^{-1}$ (entre G1 e G3) e para o tratamento com a extração da semente de Moringa oleifera a maior diferença foi $0,15 \mathrm{mScm}^{-1}$ (G1 e G3 comparados a G2).

LOPES [12], em seu estudo sobre eficiência dos coagulantes Tanino e Sulfato de Alumínio em ETA observou o mesmo comportamento para a condutividade elétrica utilizando o coagulante químico, sendo este comportamento explicado através a adição do íon alumínio na água.

Era esperado que para o tratamento onde utilizou-se o coagulante orgânico, a condutividade elétrica apresentasse valores elevados quando comparados aos valores onde empregouse o tratamento com Sulfato de Alumínio, uma vez que a presença de $\mathrm{NaCl}$ na solução coagulante natural ocasiona um aumento neste parâmetro devido ao excesso de íons presentes nas amostras de água. Porém, após a passagem da água que recebeu o tratamento com a Moringa oleifera pelos leitos filtrantes observou-se valores de condutividade elétrica, exceto em G3, menores quando comparados ao tratamento com o coagulante químico. Este comportamento é explicado devido à retenção do excesso de sólidos dissolvidos pelos dos leitos filtrantes.

Em relação à granulometria da areia, observa-se para o Sulfato de Alumínio que quanto maior a granulometria menor é a condutividade elétrica. Para o coagulante orgânico, o mesmo comportamento não ocorreu. As granulometrias menores (até $0,425 \mathrm{~mm})$ e maiores $(0,850$ a $1,70 \mathrm{~mm})$ obtiveram o mesmo valor de $0,40 \mathrm{mS} . \mathrm{cm}^{-1}$, enquanto a granulometria mediana obteve o valor de $0,25 \mathrm{mS} . \mathrm{cm}^{-1}$. Para todas as granulometrias e coagulantes o parâmetro continua maior se comparado ao valor bruto de $0,18 \mathrm{mS} . \mathrm{cm}^{-1}$.

A Portaria $N^{\circ} 5$ da Consolidação do Ministério da Saúde não estabelece valores para o parâmetro condutividade elé- 
trica e por este motivo não houve comparação com a mesma.

De acordo com a Tabela 4 as três granulometrias estudadas (G1, G2 e G3) apresentaram resultados estatisticamente distintos para ambos os coagulantes. É possível verificar que para o coagulante orgânico as granulometrias G1 e G3 apresentaram resultados iguais, já para o Sulfato de Alumínio o mesmo não ocorreu. As granulometrias G1 e G2 apresentaram médias iguais, assim como G2 e G3. Porém, G1 e G3 possuem médias estatisticamente diferentes, sendo então considerada, tal diferença, uma diferença significativa.

Anterior ao processo de filtração, os valores de eficiência de remoção de cor aparente utilizando os tratamentos com Sulfato de Alumínio e Moringa oleifera apresentavam remoções respectivas de $25 \%$ e $72 \%$.

A Figura 2 representa a porcentagem de remoção de cor aparente após o processo de filtração.

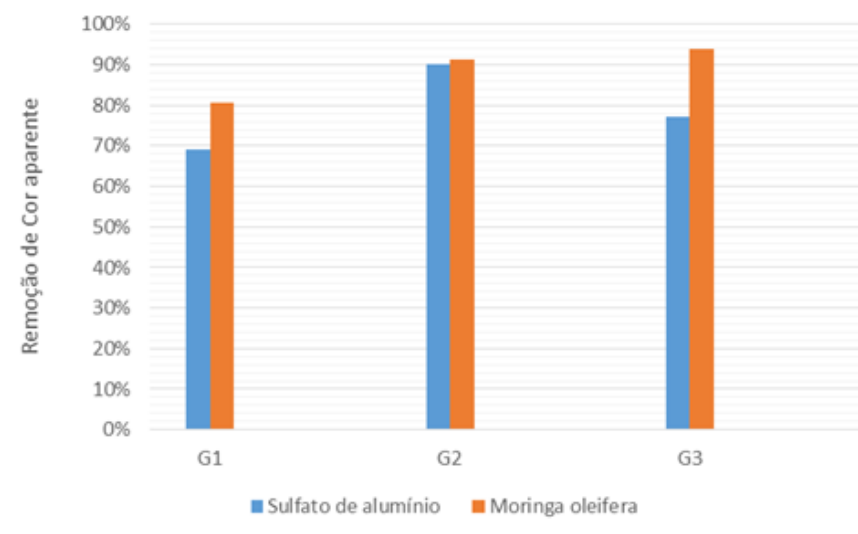

Figura 2. Remoção de Cor aparente após filtração.

Ao analisar os percentuais de remoção contidos na Figura 2 nota-se que para o tratamento com Sulfato de Alumínio a eficiência aumentou de $25 \%$ (antes da filtração) para 69\% (G1), 90\% (G2) e 77\% (G3). No estudo realizado por PEREIRA et al. [13] encontrou-se um comportamento semelhamente para o uso do coagulante Sulfato de Alumínio associado ao leito filtrante de areia com granulometria entre 0,600 a $0,800 \mathrm{~mm}$, sendo apresentada uma variação na remoção de cor aparente antes e após filtração superior a $40 \%$.

Para a extração da semente de Moringa oleifera a eficiência de remoção de cor aparente aumentou de $72 \%$ (após sedimentação) para $80 \%, 91 \%$ e $94 \%$ para as granulometrias G1, G2 e G3, respectivamente.

A granulometria que mostrou melhor resultado em relação à remoção de cor aparente foi a G2 $(0,425$ a $0,850 \mathrm{~mm})$ para o Sulfato de Alumínio (90\%), resultado superior quando comparado ao estudo de Pereira et al. [13] onde a granulometria, de 0,600 a $0,850 \mathrm{~mm}$, demonstrou eficiência de remoção de $74,65 \%$ de cor aparente no tratamento com Sulfato de Alumínio em água de abastecimento.

Para o tratamento com o coagulante natural a melhor granulometria foi a G3 $(0,850$ a $1,70 \mathrm{~mm})$ com eficiência de remoção de $94 \%$.

Apesar de todos os tratamentos apresentarem boas eficiências de remoção após a filtração, apenas o tratamento com a Moringa oleifera e filtro de granulometria G3 obteve o valor de cor aparente $(14,5 \mathrm{uH})$ dentro do estabelecido pela Portaria $\mathrm{N}^{\circ} 5$ da Consolidação do Ministério da Saúde [2] que estabelece valor máximo de $15 \mathrm{uH}$.

HENRIQUES et al. [8] observaram em seu estudo a respeito do uso da Moringa oleifera na clarificação de água para abastecimento, que o uso do coagulante natural seguido da filtração obteve valores próximos ao estabelecido pela Portaria quanto a remoção de cor aparente.

A Tabela 5 apresenta comparações de remoções médias de cor aparente para os desdobramentos para a filtração.

Tabela 5. Comparações de médias pelo teste de Tukey para os desdobramentos para Cor aparente para a filtração.

\begin{tabular}{|c|c|c|c|}
\hline \multirow{2}{*}{ Coagulante } & \multicolumn{3}{|c|}{ Granulometria } \\
\cline { 2 - 4 } & G1 & G2 & G3 \\
\hline Moringa oleifera & $3,3673 \mathrm{a}$ & $3,0341 \mathrm{a}$ & $2,6591 \mathrm{a}$ \\
\hline Sulfato de alumínio & $4,2714 \mathrm{~b}$ & $3,1550 \mathrm{a}$ & $4,0144 \mathrm{~b}$ \\
\hline \multirow{3}{*}{ Granulometria } & \multicolumn{3}{|c|}{ Coagulante } \\
\cline { 2 - 4 } & $\begin{array}{c}\text { Moringa } \\
\text { oleifera }\end{array}$ & $\begin{array}{c}\text { Sulfato de } \\
\text { Alumínio }\end{array}$ \\
\hline G1 & $3,3673 \mathrm{a}$ & $4,2714 \mathrm{a}$ \\
\hline G2 & $3,0341 \mathrm{ab}$ & $3,1550 \mathrm{~b}$ \\
\hline G3 & $2,6591 \mathrm{~b}$ & $4,0144 \mathrm{a}$ \\
\hline
\end{tabular}

Quanto às eficiências granulométricas, a Tabela 6 mostra que apenas G2 apresentou médias estatisticamente iguais para os dois coagulantes. G1 e G3 apresentaram médias diferentes entre os coagulantes, diferença que se dá uma vez que o Sulfato de Alumínio obteve os maiores valores de remoção.

Analisando a Tabela 6 nota-se ainda que a Moringa oleifera apresentou médias estatisticamente iguais para as granulometrias G1 e G2, e para G2 e G3, assim, somente G1 e G3 possuem médias estatisticamente diferentes. Logo, é possível observar que conforme aumenta a granulometria os valores do parâmetro diminuem. Já para o Sulfato de Alumínio, apenas G1 e G3 possuem médias estatisticamente iguais.

A Figura 3 apresenta a porcentagem de remoção de turbidez para ambos os coagulantes após o processo de filtração

Após o processo de filtração, observa-se um aumento significativo na eficiência de remoção de turbidez para ambos os coagulantes. Para o Sulfato de Alumínio a eficiência aumentou de $37 \%$ (após a sedimentação) para $95 \%$, 96\% e $87 \%$ para as granulometrias G1, G2 e G3, respectivamente. Esse aumento na remoção de turbidez foi esperado, pois TEIXEIRA [18], DI BERNARDO [5] e RIBEIRO KOWATA [16], constataram, em seus estudos sobre tratamento de água para abastecimento, que a filtração direta proporciona uma remoção satisfatória desse parâmetro.

Para o tratamento com a extração coagulante da semente de Moringa oleifera a eficiência de remoção de turbidez aumentou de $75 \%$ (após a sedimentação) para 97\%, 97\% e 98\% para as granulometrias G1, G2 e G3, respectivamente. PINTO HERMES [15], utilizaram em seu estudo para 


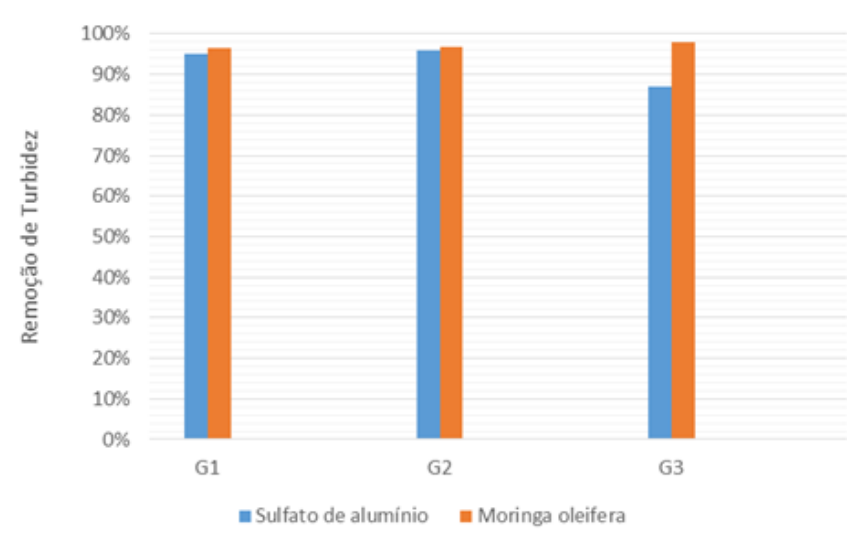

Figura 3. Remoção de turbidez após a filtração.

melhoria da qualidade da água em comunidades rurais três sistemas de tratamento, sendo eles: Sementes da Moringa oleifera seguido de filtração lenta; Sementes da Moringa oleifera sem filtração; e sistema simples de tratamento utilizando apenas filtração. Foi observado que o sistema com melhores resultados foi o de sementes seguido de filtração lenta.

A granulometria que demonstrou melhores resultados quando associada ao tratamento com Sulfato de Alumínio foi $\mathrm{G} 2(0,425 \mathrm{~mm}$ a $0,850 \mathrm{~mm})$, enquanto que a melhor granulometria em associação com o coagulante natural foi G3 $(0,850 \mathrm{~mm}$ a $1,70 \mathrm{~mm})$. Tais associações também foram as melhores no parâmetro de remoção de cor aparente.

Todas as associações dos coagulantes (Sulfato de Alumínio e Moringa oleifera) com os leitos filtrantes (G1, G2 e G3) apresentaram valores de turbidez dentro do padrão estabelecido pela Portaria No5 da Consolidação do Ministério da Saúde [2] que estabelece turbidez máxima de 5uT, exceto a associação entre o coagulante inorgânico e o leito filtrante G3.

A Tabela 6 apresenta a comparações de médias de turbidez para os desdobramentos para a filtração.

Tabela 6. Comparações de médias pelo teste de Tukey para os desdobramentos para Turbidez.

\begin{tabular}{|c|c|c|c|}
\hline \multirow{2}{*}{ Coagulante } & \multicolumn{3}{|c|}{ Granulometria } \\
\cline { 2 - 4 } & G1 & G2 & G3 \\
\hline Moringa oleifera & $3,780 \mathrm{a}$ & $4,750 \mathrm{a}$ & $2,455 \mathrm{a}$ \\
\hline Sulfato de alumínio & $5,565 \mathrm{a}$ & $4,455 \mathrm{a}$ & $14,650 \mathrm{~b}$ \\
\hline \multirow{3}{*}{ Granulometria } & \multicolumn{3}{|c|}{ Coagulante } \\
\cline { 2 - 3 } & $\begin{array}{c}\text { Moringa } \\
\text { oleifera }\end{array}$ & $\begin{array}{c}\text { Sulfato de } \\
\text { Alumínio }\end{array}$ \\
\hline G1 & $3,780 \mathrm{a}$ & $5,565 \mathrm{a}$ \\
\hline G2 & $4,750 \mathrm{a}$ & $4,455 \mathrm{a}$ \\
\hline G3 & $2,455 \mathrm{a}$ & $14,650 \mathrm{~b}$ \\
\hline
\end{tabular}

É possível observar que as granulometrias G1 e G2 apresentaram médias estatisticamente iguais para os dois coagulantes. Apesar de estatisticamente iguais, o valor da média em G1 foi maior para o coagulante sulfato de alumínio enquanto que para G2 o maior valor da média foi para a Moringa oleifera. Para o coagulante natural as três granulometrias (G1, G2 e G3) apresentam resultados estatisticamente iguais, com o melhor resultado em G3. Já para o Sulfato de Alumínio a granulometria $\mathrm{G} 3$ apresentou média diferente em relação às outras granulometrias, com o melhor resultado em G2.

\section{CONCLUSÃO}

Ao final das análises e tratamento dos dados foi possível verificar que a filtração aplicada aumentou a eficiência dos coagulantes Sulfato de Alumínio e da extração coagulante da semente da Moringa oleifera. Dentre os três diferentes leitos filtrantes analisados o que obteve o melhor desempenho em associação com o coagulante inorgânico foi o que continha a granulometria de areia entre 0,425 e $0,850 \mathrm{~mm}$. O leito filtrante associado ao tratamento com o coagulante orgânico Moringa oleifera que obteve o melhor resultado foi o que continha a granulometria G3 $(0,850$ a $1,700 \mathrm{~mm})$.

É possível observar que cada granulometria é mais eficiente para determinado coagulante, fator que deve ser considerado no planejamento de uma Estação de Tratamento de Água.

Quanto à eficiência dos coagulantes, a extração coagulante da Moringa oleifera se mostrou uma boa alternativa no tratamento de água para abastecimento quando associada a leitos filtrantes, tendo obtido resultados melhores para remoção de cor aparente e turbidez quando comparados aos valores obtidos no tratamento com Sulfato de Alumínio.

\section{Referências}

[1] APHA. Standard Methods for the Examination of Water and Wastewater. $22^{\mathrm{a}}$ ed. Washington, 2012.

[2] BRASIL. Ministerio da Saúde. Portaria de Consolidação n5, de 28 de setembro de 2017. Consolidação das normas sobre as ações e os serviços de saúde do Sistema Único de Saúde. Diario Oficial da União, Brasilia, DF, 03 de out. 2017. Seção 1.

[3] BICUDO, B. R.; PEREIRA, E. R.; VIZIBELLI, D.; RIBEIRO, T.; JANZ, F. J. L.. Ação dos Coagulantes Tanino, Moringa Oleifera e Cloreto Férrico Associados a Filtração Direta no Tratamento de Água em corpos Lóticos na Região Sul do Brasil. In: III Congresso Ibero-Americano de Empreendedorismo, Energia, Ambiente e Tecnologia - CIEEMAT. Bragança, 2017.

[4] E. Haslam. Natural Polyphenols (Vegetable Tannins) as Drugs: Possible Modes of Action. Journal of Natural Products, 59(2):205, 1996.

[5] DI BERNARDO, L. Tratamento de água para abastecimento por filtração direta. Luiz Di Bernardo (coordenador) - Rio de Janeiro: Abes, 2003. Projeto PROSAB $498 \mathrm{p}$.

[6] J. W. Baynes; S. R. Thorpe. Role of oxidative stress in diabetic complications: a new perspective on an old paradigma. Diabetes, 48(1):1-9, 1999.

[7] GHEBREMICHAEL, K. A., GUNARATIN, K. R., HENRIKSSON, H., BRUMER, H., DALHAMMAN, G. A Simples Purification and Activity Assay of the Coagulant Protein from Moringa oleifera Seed. Water Research, V. 39, P. 2338-2344, 2005. DOI: 10.1016/j.watres.2005.04.012

[8] HENRIQUES, J. A. et al. Potencial de uso da Moringa oleifera Lamarck na clarificação de água para abastecimento em comunidades difusas de áreas semiáridas. Revista Brasileira de Ciências Ambientais, Campina Grande, v. 1, n. 31, p.76-83, 2014. ISSN Eletrônico 2176-9478.

[9] S. Yamagishi; T. Matsui; H. Adachi; M. Takeuchi. Positive association of circulating levels of advanced glycation end products (AGE) with pigment epithelium-derived fator (PEDF) in a general population. Pharmacological Research, 6(2):103-107, 2010.

[10] LIMA, R. R et al. Granulometria de areias de filtros industriais para o tratamento de água de processo. Anais do XX Congresso Brasileiro de Engenharia Química - COBEQ 2014. São Paulo, 2014. 
[11] A. H. Teixeira; M. M. Bezerra; H. V. Chaves; D. R. Val; S. M. P. Filho; A. A. R. Silva. Conhecimento popular sobre o uso de plantas medicinais no município de Sobral -Ceará, Brasil. Sanare Revista de Políticas Públicas, 13(1):23-28, 2014.

[12] LOPES, B. V. Eficiência de Coagulantes na Remoção de Diferentes Concentrações de Ferro e Manganês para ETA Terras Baixas. 52 f. TCC (Graduação) - Curso de Engenharia Ambiental e Sanitária, Centro de Engenharias, Universidade Federal de Pelotas, Pelotas, 20142.

[13] PEREIRA, E. R.; VIZIBELLI, D.; RIBEIRO, T.; JANZ, F. J. L.; PARTENIANI, J. E. S.. Associação da filtração direta e uso de coagulantes naturais e químicos no tratamento de água de abastecimento. In: XLVI Congresso Brasileiro de Engenharia Agrícola - CONBEA. Maceió, 2017.

[14] PHILIPPI, A. Saneamento, Saúde e Ambiente: Fundamentos para um Desenvolvimento Sustentável. Ed. Manoele. Barueri, São Paulo. 2005.

[15] PINTO, N. O.; HERMES, L. C. Sistema Simplificado para Melhoria da Qualidade da Água Consumida nas Comunidades Rurais do Semi-Árido do Brasil. Jaguariúna: Embrapa Meio Ambiente, 2006

[16] RIBEIRO, J.T.; KOWATA, E. A. Tratamento de água por filtração direta ascendente para fins de reuso. Campinas: Editora da Unicamp, 1998.

[17] ROSALINO, M. R. R. Potenciais efeitos da presença de alumínio na água de consumo humano. 2011. 85 f. Dissertação (Mestrado em Engenharia do Ambiente) - Faculdade de Ciências e Tecnologia, Universidade Nova de Lisboa, Lisboa, 2011.

[18] TEIXEIRA, A.R.. Tratabilidade de água com baixa turbidez por filtração direta ascendente e descendente. In: Congreso Interamericano de Ingeniería Sanitaria y Ambiental, San Juan, p 1-9, 2004.

[19] THEODORO, J.D. P. Estudo dos mecanismos de coagulação/floculação para a obtenção de água de abastecimento para o consumo humano. 2012. 184f. Tese (Doutorado em Engenharia Química, área de desenvolvimento de processos) - Universidade Estadual de Maringá, Maringá. 2012.

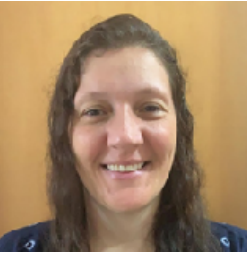

JOSEANE DEBORA PERUÇO THEODORO

Possui graduação em Engenharia Química pela Universidade Estadual do Oeste do Paraná (2002) e mestrado em Engenharia Química pela Universidade Estadual de Maringá (2004), especialização em pós-graduação em Engenharia Segurança do Trabalho pela Pontifícia Universidade Católica do Paraná (2009), Doutorado em Engenharia Química na Universidade Estadual de Maringá (2012)

e Licenciatura Plena em Matemática pela Universidade Tecnológica Federal do Paraná. Atualmente compõe o quadro de professora do curso de graduação em Engenharia Ambiental da Universidade Tecnológica Federal do Paraná UTFPR campus Londrina e professora colaboradora da Pós Graduação em Engenharia Ambiental da mesma instituição.

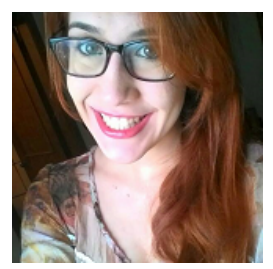

\section{BRUNA RICCI BICUDO}

Graduação em Engenharia Ambiental pela Universidade Tecnológica Federal do Paraná (UTFPR) campus Londrina-PR (2012-2018) e, através do programa de dupla-diplomação, formada em Engenharia do Ambiente e mestre em Tecnologia Ambiental (2016-2018), ambos pelo Instituto Politécnico de Bragança (Portugal).

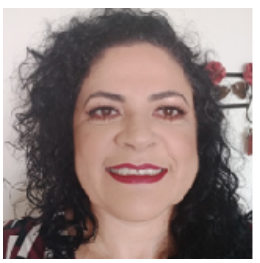

EDILAINE REGINA PEREIRA

Graduação em Engenharia Agrícola pela Universidade Estadual de Campinas-UNICAMP (1999 2000), Mestrado em Agronomia pela Escola Superior de Agricultura Luiz de Queiroz - ESALQ/USP (200-2002) e Doutorado em Agronomia pela Escola Superior de Agricultura Luiz de Queiroz ESALQ/USP (2002-2006). Possui Pós Doutorado pela UNICAMP (2007 - 2009) e pelo período de 2007 à 2011 foi Pesquisadora Colaboradora da mesma. Atuou no quadro de Pesquisador na Empresa pelo programa RHAE / CNPq na empresa Solinova.

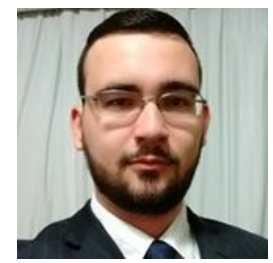

\section{FELLIPE JHORDÃ LADEIA JANZ}

Graduação em Engenharia Ambiental ( com formação na Universidade Tecnológica Federal do Paraná - UTFPR, campus Londrina. Mestrando do Programa de Pós Graduação em Engenharia Ambiental (PPGEA) da UTFPR, campus Londrina (em andamento). Atualmente participa do grupo de pesquisa CNPq Tratamento de água e efluente.

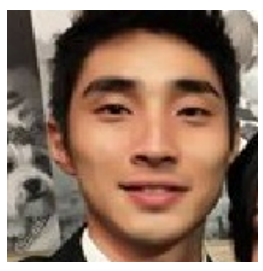

RENATO AKIRA IOSHIMURA

Graduação em Engenharia Ambiental (20102016) pela Universidade Tecnológica Federal do Paraná (UTFPR), campus Londrina, e formação complementar em Environment Studies (2015) pela Portland State University (PSU), Oregon, Estados Unidos, como bolsista pelo programa Ciências sem Fronteiras, Coordenação de Aperfeiçoamento de Pessoal de Nível Superior (CAPES),

Brasil. 